\title{
Beyond Death and Mourning in A Dark Song and We Are Still Here
}

\section{BY AgnieszKa KotwasińsKa}

\section{Abstract}

Drawing on Ewa Domańska's theory of necrovitalism (2017), Rosi Braidotti's works that engage with life/death 'dichotomy' $(2006 ; 2008 ; 2013)$, and affect theories, I hope to show how normative understanding of death and mourning, typical for horror cinema as such, are questioned and transformed through an affective engagement with spectral soundscapes in two recent horror films - A Dark Song (2016) and We Are Still Here (2015). To a large extent, both films replicate normative understanding of what constitutes a reasonable occasion for grieving: the sudden and seemingly unjust death of a child. A child's lost life, often seen as the pinnacle of felt grief, is then mourned passionately by the mother (rather than the father), whose determination and intuition guide her over the life-death threshold in order to reunite with her dead child or find some kind of closure. And yet rather than stopping at representing bereavement as a finite process, these films incorporate mourning into their cinematic language and use it to comment on the limits of Western definitions of death and life after death. In both films, encounters with otherworldly necropersons (to borrow Ewa Domańska's term) disturb the zoe/bios distinction that organises Western mourning practices. More importantly, since these encounters rely on sound rather than vision, the protagonists (and the viewers) can no longer depend on scopic regimes of knowledge and are encouraged to think/feel about death differently.

\section{KEYWORDS}

Horror cinema, grieving, the dead, sound, zoe/bios, necroperson

Agnieszka Kotwasińska is an assistant professor at American Studies Center, University of Warsaw. She has a doctoral degree in literary studies from the University of Warsaw and specializes in Gothic and horror studies, gender studies and queer theory, and feminist new materialism(s). 


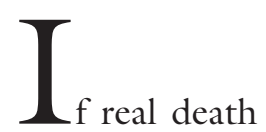

is, as Vivian Sobchack argues, "a sign to end all signs" (2004, 233), where does this leave fictional representations of death and dying? Fictional death is experienced as abstract, even "irreal" (ibid., 241). And yet, phenomenological and affective readings of horror cinema (Aldana Reyes 2016; Hanich 2010; Shaviro 1994) point to multi-layered embodied and cognitive encounters emerging in cinema which cannot easily be reduced to the classic film studies triad: spectator, camera, and image.

Representation, long linked with scopic regimes of power and a Western (over)reliance on sight as a privileged organ in the meaning-making processes (Rizzo 2012), does not account sufficiently for encounters with intrinsically unrepresentable agents such as the dead. Two recent independent horror films, the Irish-Welsh A Dark Song (2016) and the American We Are Still Here (2015), while probing the limits of visual representation, use sound in order to show how normative understanding of death and mourning, in themselves two emblematic themes of horror cinema, can be effectively questioned and transformed through affective and synaesthetic engagement with the cinematic body. ${ }^{1}$ The central place accorded to sound effects in horror cinema is intimately linked with the genre's development (Spadoni 2007), and sound often acts as a counterpart to image, a corporeal entrypoint for the experience of fear, dread, shock, and terror (Hanich 2010). ${ }^{2}$ The two films in question employ sound effects in two distinct ways: the conventional use of ominous music and jarring sound effects, meant to disturb the viewers and whet their epistemological curiosity (what will happen, who will appear) and the more elusive use of disembodied voices which are never complemented (or explained) with corresponding images.

As most ghost stories attempt to prompt fear by alternately allowing for and refusing the possibility of seeing "the things that go bump in the night", most narratives culminate in a visual epiphany which finally explains the eerie sounds, unexplained phenomena, unease and uncanny feelings experienced by the characters. And while $A$ Dark Song and We Are Still Here do reveal their monstrous figures at some point, neither gives bodies to the voices of the dead. The encounters with the dead in the two productions rely on sound rather than vision, so that the protagonists (and the audience) cannot depend on ocular knowledge and so are encouraged to think about death differently.

To a large extent, both films replicate normative understandings of what constitutes a reasonable occasion for grieving: the sudden and seemingly unjust death of a child. A child's lost life, often seen as the pinnacle of the grief experience, is then mourned passionately by the mother (rather than the father), whose determination and intuition guide her over the lifedeath threshold in order to reunite with her dead child or find closure. And yet rather than stopping at representing bereavement as a totalising and heavily feminised process, these films incorporate mourning into their cinematic language and use it to comment on normative understanding of kinship as well as on the limits of Western definitions of death and life after death.

While the two films are firmly situated in the Gothic tradition of ghost stories, the Gothic mode of spectrality is a normative and restrictive one in that it affirms heteronormative family values and strict gender roles (especially in terms of totalising motherhood), highlights narrow definitions of what successful mourning should look like (moving forward from one's grief, being compassionate, offering forgiveness), and favours cognition (ghosts need to be 
understood in order to be exorcised). Feminist and queer horror scholarship challenges some of these assumptions: Linda Williams (1991) and Barbara Creed (1993) look at how corporeality is always entangled with cognition both on screen and in the movie theatre, and Carol J. Clover (1992) and Jack Halberstam (1995) offer powerful reinterpretations of gender dynamics in popular horror narratives. Still, their overreliance on psychopathological readings (rooted in Freudian and Lacanian psychoanalytic theories) often results in a somewhat calcified understanding of gender and sexuality and a much stronger emphasis placed on deep structures than on affectivity and the bodily dimension of experience.

For these reasons, the present article moves the critical focus from traditional film theory to applied hauntology, affect theory of horror cinema, and feminist new materialisms. ${ }^{3}$ In order to trace how the two films approach death as a transformative continuum of $z o e$ rather than the rapid and unambiguous end of bios, I will also be drawing on Ewa Domańska's theory of necrovitalism (2017) and Rosi Braidotti's neovitalism (2006; 2008; 2013). Whereas life understood as bios stands for the discursive understanding of the human as individual, unique, and tragically finite, zoe refers to the nonhuman, the animal, the ever-selfreplenishing 'nature' of life. Death, which marks the definite end of bios, does not necessarily mean the end of zoe; however, Judeo-Christian thought recognises only the former as the truly grievable and recognisable form of human life. In both films, encounters with the dead disturb the zoe and bios distinction which organises Western mourning practices by shifting the emphasis from recognisably human beings to simultaneously more-than- and less-thanhuman agents.

By elevating zoe, that "monstrous energy" (Braidotti 2006, 208), a wondrous "obscenity" and "scandal" of the embodied subject, Rosi Braidotti casts death as just another "aspect of life" (2008, 178). In doing so, she rejects "the metaphysics of finitude" which "sacralizes death as the defining feature of human consciousness" and approaches zoe only in terms of human mortality. Braidotti's project of sustainable ethics "does not deny the reality of horrors", but it emphasises "the vital powers of healing and compassion" (2013, 132).

While Ewa Domańska acknowledges Braidotti's writings only in passing, it is difficult not to notice a certain semblance between Domańska's theory of necrovitalism and Braidotti's neovitalism. But where Braidotti enfolds death info life processes and, in a way, loses track of death in its manifold cultural and political meanings, Domańska reverses neovitalist directionality by emphasising the generative aspects of death such as the possibilities of interspecies transformations and necro-ethics of respect and reciprocity activated by death. In doing so, Domańska finds a new way of thinking about death - she neither posits death in terms of an ultimate threshold that organises human understanding (Agamben), nor reduces death to just another form of life (Braidotti).

\section{The Limits OF THE Gothic Spectrality}

Narratives structured around spectral visitations and encounters with the dead easily stumble into a Gothic mode, whether they are subsumed by horror subgenres or are categorised as dramas, supernatural thrillers, or ghost tales. Here, the Gothic stands for a violent return of the repressed, a secret from the past invading the present moment, "a Gothic vestigiality" (Spooner 2010,246 ), and, most crucially, a family drama that needs to be addressed (Williams 1995). The plots of ghost stories are simple: vengeance is required for someone's violent death, retribution/restitution is demanded for disturbing the peace of the 
dead, or the dead need the living to help them find peace and/or enter the afterlife. The vast majority of ghost stories and haunted house narratives deal expressly with loss and mourning, bereavement and melancholia.

Horror films reinforce normative understandings of death and dying. Late twentieth- and early twenty-first century images of death, widespread in mass media and popular entertainment, highlight death as sudden, untimely, and unjust. Death is, first and foremost, associated with wars, natural disasters, terrorist attacks, murders, and tragic accidents, which also means that popular media accounts and mainstream political discourses portray only certain subjects as truly grievable (Butler 2006). The political category of grievability (a condition of being worth someone's grief) is enmeshed with social and cultural denaturalisation of death over the course of the twentieth century. While so-called natural death has become intensely private, uncanny, and almost shameful, sudden, spectacular public deaths have become a staple of TV news and catastrophe porn (Sobchack 2004). Thus, death seems more grievable when it happens to a young body or what Sobchack calls, "a hard body", one that is clean, fit, and desirable in all its normative glory $(2004,231)$, an idea clearly present in horror cinema, which consistently focuses on the unfortunate demise of young able-bodied white people.

There is a clear gradation as to who is worthy of being contacted or brought back to life in horror. No-one mourns the death of an elderly grandmother and risks their own life trying to talk to her ghost. Thus, the majority of horror films that deal with loss focus on the death of children, spouses/partners, close friends, and, in rarer instances, other kin. Women are overrepresented as mourners, especially as grieving mothers, reinforcing Western perception of women as deeply intuitive, liminal, both grotesquely corporeal and otherworldly (which, taken together, makes them more susceptible to the anti-modern burst of the supernatural). Finally, via the historical association of middle- and upper-class white femininity with domesticity and the private sphere over the course of the nineteenth century, the house, portrayed as both a refuge and a prison for women and their children, has become a common fixture of contemporary haunted house narratives and ghost stories.

Both A Dark Song and We Are Still Here do not stray far from the Gothic sensibility in the sense that both are ghost stories taking place in haunted houses, with grieving mothers explicitly positioned as the most suitable subjects for supernatural intervention. In terms of their plot and narrative choices, characterisation, and overall aesthetics, both productions stay within the parameters established by the Gothic fictions; seen from this angle, neither film offers a radically new insight into the workings of grief and attitudes towards the dead. And yet, setting aside the Gothic provenance of both films allows for a different approach, one that recalls Edyta LorekJezińska and Katarzyna Więckowska's “applied hauntology", which "embraces the practical uses of the spectral categories" $(2017,16)$, and thus welcomes new subjects of inquiry (previously thought as marginal, not visible or tangible enough, perhaps even illegible/illegitimate). By "disentangle[ing] the spectre from reifying generic affiliations [of the Gothic]" (del Pilar Blanco and Peeren 2010, xvi), one can potentially think of hauntings, spectrality, and ghosts as "conceptual metaphors" (del Pilar Blanco and Peeren 2013, 1) capable of illuminating and diffracting the haunted ontology of being (dead).

In a somewhat similar vein, Olga Cielemęcka looks at how dead bodies' hauntological status troubles Western dichotomies by "introduc[ing] the questions of negativity, disappearing, and non-being" $(2015,236)$. The dead body, in Cielemęc- 
ka's powerful formulation, becomes "that which is radically spectral and elusive and yet still persistently material, inhabit[ing] a border of the human-nonhuman, communicable-unspeakable, the sacred and the abject" $(2015,236)$. The becoming-absent of dead bodies, which Cielemęcka alludes to in her essay, is often reversed in fictional depictions of the dead, in which they are rather involved in the process of becomingpresent or, in a truly Deleuzian twist of theory, becoming-perceptible. ${ }^{4}$

Even though both $A$ Dark Song and We Are Still Here ultimately succumb to the allure of the visual and invite supernatural entities into their frames, I am most interested in their spectral soundscapes which deprive the eye of the pleasure of seeing/ knowing and instead ask the audience to reconsider the somewhat slippery ontoepistemology of the dead. The exact source of the dis/embodied voices heard by the mothers cannot be ascertained; the voices might belong to their dead sons, but they might instead be auditory hallucinations or mind games played on them by supernatural forces. Still, the voices, whether human or non-human or both, are not phenomena awaiting rational dissection, but rather noumena whose impact on other agents is enacted through time- and place-bound "agential cuts" (Barad 2007, 175). Jason Stanyek and Benjamin Piekut, analysing posthumous music duets and revivification of dead celebrities from a Baradian agential perspective, draw attention to the way "[p]ersonhood is always collaborative, cutting across clear distinctions of materiality/discourse, technology/organicity, and bounded lifetimes/eternal deaths" (2012, $308)$. Later, I will return to the way the somewhat exclusionary and anthropocentric concept of personhood (often equalled with bios) is undercut by the deployment of necropersonhood within the two films. Suffice to say, Stanyek and Piekut's proposition that agency is not an inherent quality of a given body (an agent) but is rather dis- tributed unevenly and unpredictably across entangled bodies (digital, mechanical, biological, intangible, animate, dead) brings into focus the intra-active processes of emerging voices (and, more generally, sound).

Sound, posited as "an emergent perception" and "an embodied system" in Mark Grinshaw and Tom Garner's theorisation of sonic virtuality, worries the clear-cut boundaries between presence and absence, as it arises via embodied cognitive processes not necessarily dependent on sound waves $(2015,2-3)$. If, in fact, sound waves are not required for sound to emerge in the first place (Grinshaw and Garner 2015, 4), then sound does not require an agent to generate it, and consequently belongs to the order of hauntology. A Dark Song and We Are Still Here probe this speculative and interstitial character of sound by denying the audience the physical presence of a speaker or a recording/reproducing device.

\section{A DARK SONG: RoAD TO ReCOVERY}

In $A$ Dark Song, a grieving woman (Sophia) asks a spiritual adviser ( $\mathrm{Mr}$. Solomon) to help her contact her guardian angel in an elaborate ritual encompassing Judaism, mysticism, Gnosticism, and Christian beliefs. She rents an old mansion in the middle of the Welsh countryside, and they lock themselves in for the duration of the ritual. The film is interspersed with images of the outside world, which remains pointedly unchanged and unperturbed by what Sophia and Mr. Solomon are doing within the house. Dark nightscapes, grassy fields, and shadowy treelines suggest a nature/culture division, but for all the greenery and seeming "naturalness" of the outside, the surroundings have in fact been continually shaped and reshaped by centuries of human intervention: deforestation, tillage, gardening, and industrialisation.

Just as the outside remains enmeshed 
with and engulfed by human forces, the house - a conventional metonymy for a "civilised" middle-class life - is never truly isolated from the non-human agents. The salt that Mr. Solomon uses to encircle the house and establish a boundary between here and there, the inside and the outside, the world and the otherworld, turns out to be quite porous. Not only a powerful deterring agent in the occult, salt is also used in purification rituals, which, to a large extent, is what the film is about. In the end, Sophia can no longer rely on the binary divisions (however illusory) that organised her life before the ritual (nature-culture, inside-outside, and, most importantly, lifedeath).

Sophia and Mr. Solomon's relationship is fraught from the very beginning. A strong undercurrent of class- and gender-related resentment fuels his attitude towards her he disparages that Sophia is just another "stupid little posh girl", bent on misusing the occult and misappropriating its mighty powers for lowly "girlish" gains. It is not until she admits that she needs his help in completing the infamous Abramelin Operation in order to hear her dead child's voice that he graciously agrees to take all her savings and guide her through the process. ${ }^{5}$ Throughout the ritual he remains verbally abusive, obnoxious, and patronising, and establishes his dominance over Sophia through small cruelties and humiliations (one of such acts segues into outright sexual abuse). The harrowing months-long ritual is physically and mentally taxing: Sophia fasts, goes without water, sleep, or bathroom breaks for days at a time, all the while meticulously writing spells, drawing sigils, learning German and French, meditating, and occasionally taking various poisons and drugs to facilitate the ritual.

The major part of the film takes place within the rented house, where particular rooms are slowly de-associated with middle-class family lifestyle and are instead geometrically bound with specific stages of the ritual. Instead of tight shots and closeups suggesting a cramped, claustrophobic atmosphere, the camera offers quite a few full shots, pointing to the size of rooms in the beautiful old house and to the expansiveness of the ritual which takes over even the most mundane domestic spaces (kitchen, bathroom). Interestingly, many shots are low-angled, and the characters are seen lying, sitting, squatting, or kneeling on the floor, which only serves to further undercut the sense of anthropocentric mastery of the two people locked in an enormous house. It is worth underlining that the oft-invoked tenets of evolutionary determinism - an upright position and bipedalism - have been and still are associated with the ability to reason, sanity, and civilisational development, which in turn position the educated abled-bodied white man as a paragon of health and rationality.

By showing Sophia and Mr. Solomon from the floor up, Cathal Watters, the cinematographer of $A$ Dark Song, suggests an alternative framework of reference, one associated not only with Middle-Eastern and Kabbalistic knowledge-production, but also with the non-human. After all, the audience sees the two characters from a perspective that could belong to an insect, an inanimate object (a toy, a candle), or a speck of dust. In one telling scene, in a low-angled shot, Sophia's feet are seen walking down a corridor, but then she turns back, stoops, and picks up pink flowers lying on the carpet. The outside intrudes onto the inside - petals and flowers appear in the midst of winter inside a locked house. Almost all of Sophia's encounters with the non-human and/or the supernatural involve her bending to pick something up, crouching, lying, or sitting. It is only during the final encounter with her guardian angel (a towering figure that fills the entire room even though it is on one knee) that she stands upright and symbolically regains her humanity.

The road to recovery is not easy, howev- 
er. After a gruelling couple of months of ineffective rituals, Sophia admits to having lied at the very beginning. Rather than simply contacting her dead son via her guardian angel, she actually wants to ask the angel for vengeance against the teenagers who killed her son in a botched occult rite. Because the Abramelin Observation has thus been tainted, Mr. Solomon drowns Sophia in a bathtub and then revives her in order to cleanse her spirit. A scuffle ensues in which he is accidentally stabbed. Because they cannot leave the house, the wound becomes infected and Mr. Solomon dies. In a final showdown, damned souls drag Sophia to the basement and torture her; she manages to escape only when she utters the words "I'm sorry". Upon meeting her guardian angel, she eventually asks for the power to forgive, not for vengeance, and is thus allowed to leave the house and regain her place in the outside world.

The ending strongly suggests that, at least at a level of signification, dealing with tragic loss and the dead remains enmeshed in normative and totalising narratives of grief and mourning. Firstly, forgiveness and contrition are highly valued, and the ability to let go and move on with one's life is established as the true goal of mourning. Secondly, Sophia's grief as a mother trumps everything else. Unsurprisingly, the fact that Sophia's road to recovery resulted in $\mathrm{Mr}$. Solomon's death is glossed over. Before leaving the house, she gives him a water burial in a nearby pond, somewhat perversely re-enacting the moment when he drowned her in a bathtub. Sophia's perseverance, obsessiveness even, speaks of motherhood as a totality, a monolith that does not allow for anyone or anything besides the mother-child relationship; the film normalises this totalising vision, which leaves little, if any, room for Sophia as a nonmother, as someone other-than-a-mother. Thirdly, the living and the dead are clearly separated into two incompatible realms, and any potential encounter between them has to be forced via the occult. Lastly, even though Sophia seems to have found solace, she requires an incredibly costly intervention to move on, which is not something every grieving parent can possibly afford (emotionally, physically, or even financially). The multi-layered cost of the ritual also suggests that one has to literally force supernatural entities to lift the pain, because doing it on one's own (or with family help) seems even more daunting.

However, on the level of affective resonances that the viewing of $A$ Dark Song engenders, a very different engagement with death and the dead is evident. For instance, non-diegetic music effectively questions the separation between the dead and the living, and the human and the non-human, by highlighting sounds onomatopoeically reminiscent of animals and forest sounds (creaking wood, low-frequency drumming, mating calls) as well as sounds unfamiliar to audiences accustomed to Western music sounds that appear jarring and non-human. The composer Ray Harman's music is based on minimalist, acoustic, wooden instruments such as the bass, the viola, the guembri - a North African string instrument, and the daft - an African drum. The director Liam Gavin asked specifically for "very primal, repetitive and simple" sounds (Harman 2017), which is why Harman used very small groups of instruments (three or four per arrangement) to reflect the "primal" origins of the ritual and its repetitive nature. Of course, "primal" is hardly an apt expression, as the origins of the ritual actually refer to the rich medieval culture of the Jewish diaspora in Europe. Harman's score does not, however, tap into this particular cultural sensibility. Instead, his music brings into focus the inseparability of the human and the non-human by highlighting "primal" (meaning non-orchestral, unaltered, and austere) sounds sounds which are not easy to trace for audiences unused to them and which confuse 
the listeners as to their function (diegetic or non-diegetic?) and origin (human-made or animal-made?). ${ }^{6}$

The defamiliarisation of the grieving process continues in two pivotal scenes during which Sophia finally gets to hear her dead son's voice. In both cases, the voice appears behind a door and implores her to open it and let the speaker in. Sophia, educated in the minutiae of the ritual, knows that in all probability, it is not her son Jack, but rather a demon or a damned soul trying to trick her. And yet, both times she talks with the voice as if it were her son, telling him that she misses him and is happy to hear him again. The voice, though radically cut off from its source, is tangible enough for Sophia to engage with it. In a way, the voice constitutes enough of Jack to have an agency recognised by Sophia.

Sophia sees her son only in the last act, as he is led by an old hag in ragged clothing, but he does not speak, and it remains unclear whether it is truly her son, his spectral self, or a demonic trick. Jack has appeared briefly before in Sophia's hallucinations or spectral visions, but, importantly, he is never simultaneously seen and heard. And since no-one is able to discover who/what that voice really belongs to, Jack's voice becomes a dis/embodied presence as absence, a figure of spectrality, a necroperson. In Domańska's theory, a necroperson is "an agent capable of introducing changes to the surrounding" (2017, 29), which refers first and foremost to the unapologetic physicality of the dead - their skeletons, ashes, decomposing corpses, carbon-based humus, which pervade the spaces assumed to be just for/of the living. In $A$ Dark Song, however, such direct materiality of the dead is ignored by Sophia, as audiences can only assume Jack's body had been buried long before the ritual began, most probably in a different part of the country.

And yet, Jack's voice insists on being heard and felt, and his spectral presence as absence troubles the dead/alive dichotomy when it pushes its way into the material world and materialises itself in a reality that is already destabilised by the ritual. Similarly, the flowers and petals that Sophia finds in the locked house, whether fresh or dried, are already dying/dead and thus could be seen as reminders of the materiality of the dead, and their refusal to stay politely hidden and separated from the living.

\section{We Are STILL HerE:}

\section{A Happy Reunion with the Dead?}

In We Are Still Here, the New England Gothic (a variety of American Gothic associated with eerie North-East small towns, strange cults, and doomed middle-class families) is undercut by explicit gore and graphic special effects (practical effects such as makeup as well as prosthetics and computer-generated imagery, or CGI). The year is 1979: Annie and Paul, a middleaged middle-class white couple, move into an old Victorian house in a peaceful New England countryside. Similarly to A Dark Song, a bleak landscape seems indifferent to their plight as grieving parents. Wide panoramic shots prompt a nostalgic longing for 1970s small-town America, but the cinematographer Karim Hussein uses zooming to suck the audience into the landscape, as if the pastoral scenery was violently grabbing and attacking the viewer.

Annie and Paul have left the city in order to cope with the loss of their adult son, Bobby, in an accident. Almost immediately upon arrival, Annie feels a presence in the house which she takes to be her son's ghost. The camera is more voyeuristic and active than in A Dark Song, following the characters, lurking in corners and zooming in on clues that only the audience can see. The house feels cramped and stuffy, which is further exacerbated by repeated remarks that the house smells of burning. Early in the film, the audience learns that the basement is home to entities in the form of 
burnt and yet still-burning humanoids. It is subsequently revealed that 150 years earlier, during the construction of the house, the builders exposed the lair of ancient gods who demand sacrifice every 39 years. The townsfolk killed the first family who had moved in - the Dagmars - and ever since, the Dagmars act as the gods' deathly emissaries. They are tasked with killing a family every 39 years, and if they do not or the town does not provide them with new victims, the gods punish the town with disease, famine, or bad crops. The Dagmars kill two couples - Bobby's friend Harry and his girlfriend, and Harry's parents, who come to visit Annie and Paul. However, these offerings do not count because the gods require a sacrifice to be the family that has officially claimed the house for themselves. Strangely, the Dagmars refuse to kill Annie and Paul, which prompts the town people to attack the house. One must wonder why the Dagmars spare Annie and Paul: is it because Annie and Paul are not considered a real family without their son or because the Dagmars actually feel sympathy for their loss. By the end of the film, the Dagmars are finally able to revenge themselves on the town, whereas the grieving couple decides to stay in the house and join the Dagmars, as their son Bobby calls to them from the basement.

Once again, the narrative focuses on a (hetero)normative view of death and attitudes towards the dead. The film paints motherhood as a unique bond between a mother and her child, as Annie is burdened with a special insight and connection to her dead son. She 'brings' Bobby with her and is well aware that they cannot outrun their memories by leaving the city. It is Paul who insists that Bobby does not haunt the house (or Annie) but will rather forever remain in their hearts as a collection of memories, and he is sure that they can fix any problems with their new house (the lingering smell, the faulty boiler, a broken photo frame), which now stands metonymically for their incomplete nuclear family unit. Annie is much more hesitant and intuits that without a child they are unfixable, which is why she envies the Dagmars their love and 'togetherness'. After all, even death could not tear them apart and they have spent the last 130 years haunting and killing families that dared to move into their old house. In the end, heteronormative kinship trumps both death and life. The last shots show the still-smouldering Dagmars holding hands in a grotesque pastiche of nuclear family life, while Annie follows Bobby's voice into the basement with Paul soon disappearing after her.

As in A Dark Song, it is by no means certain that the voice actually belongs to Bobby. At no time does the audience see him or his ghost. In the closing shot, the camera is positioned at the bottom of the basement stairs (thus assuming the perspective of whoever/whatever is standing there). Paul looks into the basement, smiles with relief, and says "Hey, Bobby". Earlier in the film, May, Annie's friend and a hippie medium, helps the couple ascertain whose spectral presence can be felt in the house. May is sure that the presence is not Bobby's, but rather belongs to "something infernal" that wants to keep Annie and Paul there. In the third act, Bobby's ghost can be heard telling his parents to leave the house. A paradox ensues: why is Bobby first warning them to leave the house and then summoning them to the basement so that they can presumably die there and spend their eternity as ghosts? Will the two families coexist happily, or will Annie, Paul, and Bobby release the Dagmars from their duty and take over the sacrificial killing? Is Bobby really there or are the ancient gods manipulating Annie and Paul into becoming their new servants?

One way of looking at We Are Still Here is through the motif of a nuclear family in crisis, a common theme in twenty-first-century American horror cinema. ${ }^{7}$ In this reading, the ending suggests a happy, if diffi- 
cult, reunion and a second chance at 'togetherness' for Annie and Paul. From this perspective, the death of a child inevitably equals the dissolution of the family, which is felt especially acutely by the mother. The grieving process can be resolved only by an otherworldly intervention or, simply put, by further proliferation of death among the remaining family members. In a way, Bobby, being dead, is reduced to either a clichéd, painfully vague 'memory collection' or a stereotypical ghost clinging to his mother.

For this very reason, his voice plays such an important role in challenging the normative understanding of grief in the film. As a dis/embodied voice, Bobby is neither simply a memory nor a spectral visitor, but rather occupies a hauntological in-between. His voice is materially perceptible but lacks a visible identifiable source, which would mollify the audience's epistemological unease. As Braidotti eloquently puts it, "Being dead does not reduce one to the status of figment of other people's imagination, but it dissolves the self into interconnected continuum with nature as One" (2006, 238 ). The audience is forced to rely on second-hand observation and trust not only Annie and Paul's parental intuition but also their senses. Arguably, because of the frequent verbal references to unpleasant smells (especially the burning smell) as well as visual markers of the burning bodies of the Dagmars, We Are Still Here relies heavily on synaesthetic engagement with the cinematic material - haptic, olfactory, aural, and visual sensations are not only strengthened but are allowed to reinforce each other. ${ }^{8}$

The pervasive smell of burning bodies coupled with the fact that Annie and Paul are last seen descending into the basement to join Bobby suggest a hellish ending for their reconstituted nuclear family unit. More to the point, the Dagmars, for all their cosy 'togetherness', have killed two couples - Harry and his girlfriend were punished for engaging in premarital sex and Andy and May for their relaxed attitude towards their son and for interfering in the Dagmars' ghostly affairs. Somewhat ironically, it would seem that the only place for a nuclear family, both in its starkly Victorian and more relaxed contemporary version, is underground, locked away in a basement along with the other skeletons in the closet (or the boiler).

\section{CONCLUSION}

Both films hint at how zoe, posited in neovitalist terms, problematises the dead/ alive dichotomy. One way of looking at these two films is precisely through the lens of zoe which begins its 'life' after bios 'dies'. Zoe in both productions masquerades as bios; that is, as identifiable individuals who were dear to the protagonists, which explains why Jack's and Bobby's voices were recognised as such by their mothers. Of course, while Braidotti locates zoe after death in the "material and embodied frame" as well as "bacteria, fluids of all kinds and third parties" $(2006,239)$, zoe in the analysed horror films belongs to a hauntological register. Still, in a more physically-inclined understanding of zoe, the sons' dis/embodied voices also suggest a transformative process; they signal a need to let go of bios in its life-centric meaning: anthropocentric, laden with personal history and understood to be exclusively human, unique and linear. In both films, the voices of the dead suggest a wider community of the dead - transformed, otherworldly, supernatural, non-human, more-than-human, no-longer-human, or at the very least, unable to be contained by the identities accorded them before, "Jack" and "Bobby".

Still, Braidotti's neovitalism puts too much emphasis on life rather than death, thus causing death to recede into the horizon of immanence. If death has already happened, and it "does not lie ahead but is already behind us" (Braidotti 2006, 211), then it follows that "the attachment to life 
and the fear of dying, feelings of loss, melancholia and grieving" are "nothing more than an anthropocentric, neurotic anxiety" (Cielemęcka 2015, 239). I agree with Cielemęcka's reflection that the neovitalist model of life and death evacuates the personal and the individual from the moment of dying, which is something that the two films persistently and obsessively return to in the form of their dis/embodied voices. Domańska's necrovitalist theoretical model, on the other hand, puts more weight on the materiality, indelibility, and transversality of the dead. Of course, one could argue that both models are valuable in their own right and that both are equally limited by their conceptual omissions, accentuations, and intensities. Still, even a brief look at Braidotti's The Posthuman (2013) reveals a renewed need to talk about the necropolitical ab/uses of the living and the dead, new ways of dying, bioethics, bio-piracy and bio-terror. For this reason, a necrovitalist perspective might be actually better-suited to the discussion of the dead in horror cinema, as it effectively disrupts the anthropocentric and life-centric understanding of death and advocates for a radically posthuman, queerly-inflected experience of dying in a late capitalist world.

Ultimately, in terms of their narrative choices and character development, the two films rely on a (hetero)normative framework of grieving and attending the dead, in which motherhood and the nuclear family are privileged sites of mourning. Yet, despite the somewhat disappointing resolutions (forgiveness as an end to pain in $A$ Dark Song and a happy family reunion in We Are Still Here), the dis/embodied voices of the dead prompt a different affective engagement with death and life after death. In this sense, shifting the focus from grieving mothers onto the objects of their grief queers normative understanding of death, family, and motherhood. The dead children, who remain neither entirely dead nor childlike, exist in an onto-epistemological suspension, present only through sound, yet pointedly absent from sight. Their necroagency both exceeds and challenges their mothers' parental attachment, as their uncertain status as ghosts, demons, or actual people remains unsettled and unsettling. The persistence of the dead cannot be contained by the feel-good narratives that stress closure and finitude; if anything, the voices of the two dead sons - voices whose true origin and ontological status are suspended - bring about an encounter with the dead, which, in turn, emphasises their zoe-driven post-life existence and their persistent presence as absence.

\section{Notes}

1. See also Shaviro (1994, 257): "The cinematic body is then neither phenomenologically given nor fantasmatically constructed. It stands at the limits of both of these categories, and it undoes them. (...) Film theory should be less a theory of fantasy (psychoanalytic or otherwise) than a theory of the affects and transformations of bodies".

2. Hanich writes about "vivid sound-supported moving images of threatening acts of violence or a dangerous monster" (original emphasis) in terms of an aesthetic strategy he calls 'direct horror' (2010, 82).

3. While Deleuzoguattarian schizoanalytic readings of horror cinema are often intertwined with affect theory, for clarity I have decided against engaging with them in this paper.

4. One of the ways in which Braidotti explains becoming-imperceptible is via becoming friends with "impersonal death" and agreeing to one's "loss of identity" $(2006,262)$; however, horror cinema often underlines the unwillingness of the dead to stay silent or to merge with their environment. 5. Mr. Solomon's magic framework is inspired by Abraham of Worms' The Book of Abramelin, a Kabbalistic grimoire written in 14th or 15th century. The ritual takes between six to eighteen months and requires absolute isolation and careful observance of a number of complex rituals.

6. As far as contemporary horror cinema is concerned (from the 1960s onward), Bernard Herrmann's score for Psycho (1960) established a num- 
ber of conventions that came to characterise horror cinema soundtrack for decades to come (Hayward 2009, 10). Philip Hayward argues that orchestral score is so entrenched in horror genre that "alternative approaches primarily occur at the edges of the genre" $(2009,10)$.

7. See also Jackson (2014) for a longer discussion of the family in contemporary horror

8. See also Sobchack (2004) and Kennedy (2000) for an analysis of cinematic aesthetics and its connection to human senses.

\section{REFERENCES}

- Aldana Reyes, X. 2016. Horror Film and Affect: Towards a Corporeal Model of Viewership. New York: Routledge.

- Barad, K. 2007. Meeting the Universe Halfway: Quantum Physics and the Entanglement of Matter and Meaning. London: Duke University Press.

- Braidotti, R. 2006. Transpositions: On Nomadic Ethics. Cambridge: Polity.

- Braidotti, R. 2008. The Politics of Life as Bios/Zoe. In: Smelik, A. and Lykke, N. eds. Bits of Life. Feminism at the Intersections of Media, Bioscience and Technology. University of Washington Press, 179-196.

- Braidotti, R. 2013. The Posthuman. Cambridge: Polity.

- Butler, J. 2006. Precarious Life: The Powers of Mourning and Violence. London: Verso.

- Cielemęcka, O. 2015. All Things Spectral. Somatechnics. 5(2), 234-254. DOI:

https://doi.org/10.3366/soma.2015.0163

- Clover, C.J. 1992. Men, Women, and Chainsaws: Gender in the Modern Horror Film. Princeton University Press.

- Creed, B. 1993. The Monstrous Feminine: Film, Feminism, Psychoanalysis. London: Routledge. - A Dark Song. 2016. Dir. Liam Gavin. Samson Films. DVD.

- Domańska, E. 2017. Nekros. Wprowadzenie do ontologii martwego ciata. Warszawa: Wydawnictwo Naukowe PWN.

- Grimshaw, M. and Garner, T. 2015. Sonic Virtuality: Sound as Emergent Perception. Oxford: Oxford University Press.

- Hayward, P. 2009. Introduction: Scoring the Edge. In: Hayward, P. ed. Terror Tracks: Music, Sound and Horror Cinema. London: Equinox, 113.

. Halberstam, J. 1995. Skin Shows: Gothic Horror and the Technology of Monsters. Durham: Duke University Press.

- Hanich, J. 2010. Cinematic Emotion in Horror Films and Thrillers: The Aesthetic Paradox of Pleasurable Fear. New York: Routledge.

- Interview with Ray Harman. 2017. Ray Harman: Nurturing Ireland's Film Industry with Music. [Online]. Score It Magazine. 27 July. [Accessed 10 September 2018]. Available from: http://magazine.scoreit.org/nurturing-irelandsfilm-music-scene-ray-harman/

- Jackson, K. 2014. Gender and the Nuclear Family in Twenty-First-Century Horror. London: Palgrave Macmillan.

- Kennedy, B.M. 2000. Deleuze and Cinema: The Aesthetics of Sensation. Edinburgh: Edinburgh University Press.

· Lorek-Jezińska, E. and Więckowska, K. 2017. Applied Hauntologies: Spectral Crossings and Interdisciplinary Deconstructions. Avant. 8(2), 15-23. DOI: 10.26913/80202017.0112.0001 - del Pilar Blanco, M. and Peeren, E. 2010. Introduction. In: del Pilar Blanco, M. and Peeren, E., eds. Popular Ghosts: The Haunted Spaces of Everyday Culture. New York: Continuum, ix-xxiv. - del Pilar Blanco, M. and Peeren, E. 2010. Introduction: Conceptualizing Spectralities. In: del Pilar Blanco, M. and Peeren, E., eds. The Spectralities Reader: Ghosts and Haunting in Contemporary Cultural Theory. London: Bloomsbury, 1-27. - Rizzo, T. 2012. Deleuze and Film: A Feminist Introduction. London: Continuum.

- Shaviro, S. 1994. The Cinematic Body. University of Minnesota Press.

- Sobchack, V. 2004. Carnal Thoughts: Embodiment and Moving Image Culture. Berkeley: University of California Press.

- Spadoni, R. 2007. Uncanny Bodies: The Coming of Sound Film and the Origins of the Horror Genre. Berkeley: University of California Press.

- Spooner, C. 2010. Crime and the Gothic. In: Rzepka, Ch. J. and Horsley, L. eds. A Companion to Crime Fiction. Chichester: Wiley-Blackwell, 245-257.

- Stanyek, J. and Piekut, B. 2012. Deadness: Technologies of the Intermundane. In: Sterne, J. ed. The Sound Studies Reader. London: Routledge, 304-324

- We Are Still Here. 2015. Dir. Ted Geoghegan. Snowfort Pictures. DVD.

- Williams, A. 1995. Art of Darkness: A Poetics of Gothic. Chicago: University of Chicago Press. -Williams, L. 1991. Film Bodies: Gender, Genre, and Excess. Film Quarterly. 44 (4), 2-13. DOI: $10.2307 / 1212758$ 